\title{
Eye injury from exploding golf balls
}

\author{
G. NELSON
}

Sussex Eye Hospital, Brighton

Golf balls with liquid centres are liable to explode if damaged, and thus present a potential hazard to the eye. This injury was described by Duke-Elder (I954) who concluded "... Fortunately this hazard has now been removed from golf". In the past 5 years, however, several cases have been reported in the American literature (Johnson and Zimmerman, 1965; Penner, 1966; Slusher, Jaegers, and Annesley, 1967), and two further cases are described below to emphasize that these accidents though rare may still occur with serious results. Both patients suffered ocular damage which is still causing visual disability 9 months after the accident.

\section{Case reports}

Case 1, a man aged 22, was seen in August, 1969, at the Eye Department of the Royal Victoria Hospital, Belfast, after an injury to the right eye. While he was examining a golf ball which his dog had been chewing the ball exploded. He was unable to identify the make of ball.

\section{EXAMINATION}

The visual acuity in the right eye was $6 / 36$. There was a corneal abrasion, hyphaema, traumatic mydriasis, and a white plaque beneath the conjunctiva with a small puncture wound of the conjunctiva at 12 o'clock (Figure).

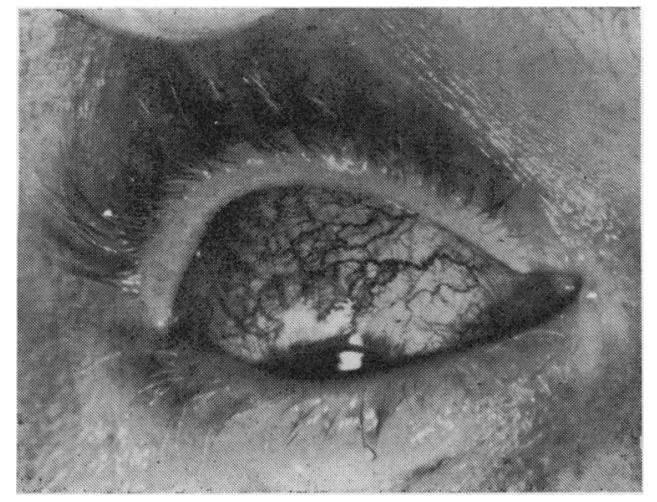

F IGURE Appearance of white conjunctival plaque

An $x$-ray of the orbit showed a "half-moon" shadow corresponding to the white plaque.

\section{TREATMENT}

Topical mydriatics and steroids were applied and the hyphaema and abrasion settled. At operation 5 days later the subconjunctival white substance was removed. Microscopy showed birefringent crystals of barium salts. 
RESULT

The postoperative course was uneventful. When the patient was last seen 9 months later, traumatic mydriasis was still present and the corrected visual acuity was $6 / 9$.

Case 2, a male agricultural research worker aged 3r, was seen at the Royal Victoria Hospital Eye Department in June, 1969. He had been examining a golf ball already partially dissected by a junior colleague when it exploded and injured his left eye. He could not identify the type of ball.

\section{EXAMINATION}

The visual acuity was $6 / 36$; there was a large corneal abrasion, multiple small intracorneal foreign bodies, hyphaema, and traumatic mydriasis.

TREATMENT

Topical mydriatics and antibiotics were applied and the intracorneal foreign bodies were removed as completely as possible 5 days later.

\section{RESULT}

The postoperative course was uneventful. When the patient was seen 9 months later the corrected visual acuity was $6 / 6$, although there were still several minute intracorneal foreign bodies. His only complaint was photophobia in bright light.

\section{Comment}

The liquid-centre golf ball is under a pressure of approximately 2,000 oz./sq. in. and if the outer coats are weakened sufficiently is liable to explode. The fluid centre consists largely of barium salts; the exact composition varies with the make of ball and is often a trade secret.

Ocular injury may result from the direct effects of the explosion or from the retention of foreign material in or on the eye.

In the first case the radio-opaque white centre was probably ejected as a fine stream which perforated the bulbar conjunctiva and lodged subconjunctivally. A considerable amount of the foreign material is still present subconjunctivally but it does not seem to be causing any marked reaction and appears to be relatively innocuous. Similarly, the intracorneal foreign bodies in the second case have not provoked any noticeable reaction.

I wish to thank Mr. J. A. Corkey and Mr. R. H. Baird for permission to examine their cases and Miss P. Shields for secretarial help.

\section{References}

DUKE-ELDER, s. (1954) “Text-book of Ophthalmology", vol. 6, p. 6582. Kimpton, London johnson, F. B., and zimmerman, L. E. (1965) Amer. F. clin. Path., 44, 533 PENNER, R. (1966) Arch. Ophthal. (Chicago), 75, 68

Slusher, м. м., Jaegers, K. R., and ANNESley, w. h. (1967) Amer. F. Ophthal., 64, 736 